\title{
In situ construction of amorphous hierarchical iron oxyhydroxide nanotubes via selective dissolution- regrowth strategy for enhanced lithium storage
}

\author{
Fangyu Xiong ${ }^{1 \dagger}$, Fan $\mathrm{Lv}^{2 \dagger}$, Chen Tang ${ }^{1}$, Pengfei Zhang ${ }^{1}$, Shuangshuang Tan ${ }^{1}$, Qinyou An ${ }^{1,3^{*}}$, \\ Shaojun Guo ${ }^{2,45^{*}}$ and Liqiang Mai ${ }^{1, *^{*}}$
}

\begin{abstract}
The low-cost and high-capacity metal oxides/ oxyhydroxides possess great merits as anodes for lithium-ion batteries (LIBs) with high energy density. However, their commercialization is greatly hindered by insufficient rate capability and cyclability. Rational regulations of metal oxides/oxyhydroxides with hollow geometry and disordered atomic frameworks represent efficient ways to improve their electrochemical properties. Herein, we propose a fast alkalietching method to realize the in-situ fabrication of iron oxyhydroxide with one-dimensional (1D) hierarchical hollow nanostructure and amorphous atomic structure from the iron vanadate nanowires. Benefiting from the improved electron/ ion kinetics and efficient buffer ability for the volumetric change during the electro-cycles both in nanoscale and atomic level, the graphene-modified amorphous hierarchical $\mathrm{FeOOH}$ nanotubes (FeOOH-NTs) display high rate capability $(\sim 650$

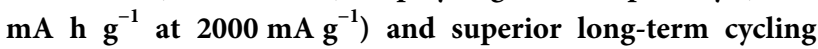
stability (463 $\mathrm{mA} \mathrm{h} \mathrm{g}^{-1}$ after 1800 cycles), which represents the best cycling performance among the reported $\mathrm{FeOOH}$-based materials. More importantly, the selective dissolutionregrowth mechanism is demonstrated based on the time tracking of the whole transition process, in which the dissolution of $\mathrm{FeVO}_{4}$ and the in-situ selective re-nucleation of $\mathrm{FeOOH}$ during the formation of FeOOH-NTs play the key roles. The present strategy is also a general method to prepare various metal (such as $\mathrm{Fe}, \mathrm{Mn}, \mathrm{Co}$, and $\mathrm{Cu}$ ) oxides/oxyhydroxides with 1D hierarchical nanostructures.
\end{abstract}

Keywords: selective dissolution-regrowth, iron oxyhydroxide, hierarchical nanotube, lithium-ion battery, anode material

\section{INTRODUCTION}

Lithium-ion batteries (LIBs) have been extensively utilized as power sources for portable electronics due to their high energy density and long lifespan. Recently, LIBs were further considered as a promising candidate of energy storage device for application in electric vehicles, hybrid electric vehicles and smart grid systems [1-4]. However, with limited theoretical capacity of graphite as most major anode material for current commercial LIBs $\left(372 \mathrm{~mA} \mathrm{~h} \mathrm{~g}^{-1}\right)$, their energy/power densities are still far away from the demand in these emerging applications [57]. Thus, the exploitation of new anode materials with higher capacity is urgent. Transition metal oxide/oxyhydroxide materials always possess higher capacity due to their conversion-type reaction mechanism, and have been considered as the next-generation anode materials for high performance LIBs [5-8]. Unfortunately, these materials always suffer from poor rate performance and instability issue owing to the sluggish kinetic and large volume change during the charge-discharge process.

Rationally tuning the nanoscale construction and atomic structures of these metal oxides/oxyhydroxides to promote their electrochemical performances becomes a research hotspot. At nanoscale, one-dimensional (1D) nanostructures can provide short ion diffusion distance, large specific surface area and continuous electron transport pathway, possessing the superiority to enhance the rate performance in lithium storage applications $[5,9,10]$. Besides, constructing hierarchical structure is able to further reduce the ion diffusion distance and in-

\footnotetext{
${ }^{1}$ Key Laboratory of Advanced Technology for Materials Synthesis and Processing, Wuhan University of Technology, Wuhan 430070, China

${ }^{2}$ Department of Materials Science \& Engineering, College of Engineering, Peking University, Beijing 100871, China

${ }^{3}$ Foshan Xianhu Laboratory of the Advanced Energy Science and Technology Guangdong Laboratory, Foshan 528200, China

${ }^{4}$ BIC-ESAT, College of Engineering, Peking University, Beijing 100871, China

${ }^{5}$ Beijing Key Laboratory for Magnetoeletric Materials and Devices (BKL-MEMD), Peking University, Beijing 100871, China

† These authors contributed equally to this work.

* Corresponding authors (emails: anqinyou86@whut.edu.cn (An Q); guosj@pku.edu.cn (Guo S); mlq518@whut.edu.cn (Mai L))
} 
crease the specific surface area, greatly improving the rate performance. Moreover, the void spaces between subunits in hierarchical structure can accommodate the volume change during the cycling and then improve the structure stability and cycling performance [9-12]. At the atomic level, metal oxide/oxyhydroxide anodes with disordered atomic arrangement possess much better ion storage ability and stability than crystalline counterparts [13]. Because the isotropic and loose amorphous structure can accommodate more Li-ions and effectively lessen the volume changes and buffer the strain during charge/discharge at the meantime [13-18]. Therefore, constructing amorphous $1 \mathrm{D}$ hierarchical nanostructures is a promising approach to improve the rate performance and cycling stability of transition metal oxide/oxyhydroxide electrode materials.

Herein, we present a new selective dissolution-regrowth strategy to obtain the amorphous $\mathrm{FeOOH}$ hierarchical nanotubes (FeOOH-HNTs) from $\mathrm{FeVO}_{4}$ nanowires (FVO-NWs). The selective dissolution-regrowth mechanism was confirmed, which can be considered as the selective dissolution of vanadium and the regrowth of FeOOH-HNTs. Moreover, this selective dissolutionregrowth strategy had been extended to make some other hierarchical metal oxide NWs from the V/Mo-based NWs. The as-prepared FeOOH-HNTs were evaluated as anode materials for LIBs and sodium-ion batteries (SIBs), and graphene was introduced to further improve the electrochemical performance, considering the poor electronic conductivity of $\mathrm{FeOOH}$. The graphene-decorated amorphous FeOOH-HNTs (FeOOH-HNTs-G) exhibit high capacity (1176 $\left.\mathrm{mA} \mathrm{h} \mathrm{g}^{-1}\right)$, excellent rate performance $\left(\sim 650 \mathrm{~mA} \mathrm{~h} \mathrm{~g}^{-1}\right.$ at $\left.2000 \mathrm{~mA} \mathrm{~g}^{-1}\right)$ and outstanding cycling stability (463 $\mathrm{mA} \mathrm{h} \mathrm{g}^{-1}$ after 1800 cycles at $1000 \mathrm{~mA} \mathrm{~g}^{-1}$ ), superior to the cycling performance of most reported $\mathrm{FeOOH}$-based materials. The superior electrochemical performance is attributed to the cooperation of hierarchical tube-like nanostructure, amorphous phase and graphene decoration, which enhances both structural stability and electrochemical kinetics.

\section{EXPERIMENTAL SECTION}

\section{Material synthesis}

The FVO-NWs and FVO-NWs/graphene composites (FVO-NWs-G) were synthesized via a hydrothermal method according to the previous reports [5,19]. The $\mathrm{FeOOH}-\mathrm{HNTs}$ were obtained by treating FVO-NWs with $\mathrm{NaOH}$ solution. The FVO-NWs $(40 \mathrm{mg})$ were added to $10 \mathrm{~mL}$ of $0.2 \mathrm{~mol} \mathrm{~L}^{-1} \mathrm{NaOH}$ solution, and the reaction was carried out under an ultrasonic environment with the frequency of $40 \mathrm{kHz}$ for $3 \mathrm{~h}$. Then, the FeOOH-HNTs were obtained by centrifugation and washed thrice with water and ethanol, respectively, and dried under vacuum at $70^{\circ} \mathrm{C}$ for $12 \mathrm{~h}$. The FeOOH-HNTs-G were obtained from FVO-NWs-G in the same manner. To demonstrate the universality of the selective dissolution-regrowth strategy, copper vanadate, cobalt molybdate and manganese molybdate NWs were selected as precursors to synthesize other metal oxides/oxyhydroxides with 1D hierarchical nanostructures by this strategy. The copper oxide hierarchical NWs were obtained from copper vanadate NWs by etching with $0.2 \mathrm{~mol} \mathrm{~L}^{-1} \mathrm{NaOH}$ solution for $3 \mathrm{~h}$. The cobalt oxide hierarchical NWs were obtained from cobalt molybdate NWs by etching with $0.02 \mathrm{~mol} \mathrm{~L}^{-1}$ $\mathrm{NaOH}$ solution for $3 \mathrm{~h}$. The manganese oxide hierarchical NWs were obtained from manganese molybdate NWs by etching with $0.05 \mathrm{~mol} \mathrm{~L}^{-1} \mathrm{NaOH}$ solution for $3 \mathrm{~h}$.

\section{Materials characterizations}

$\mathrm{X}$-ray diffraction (XRD) measurements were performed by using a D8 Advance X-ray diffractometer with a nonmonochromated $\mathrm{Cu} \mathrm{Ka} \mathrm{X-ray} \mathrm{source.} \mathrm{The} \mathrm{field}$ emission scanning electron microscopy (FESEM) images were recorded with a JEOL-7100F microscope. Transmission electron microscopy (TEM), high-resolution TEM (HRTEM) images, selected area electron diffraction (SAED) patterns and energy dispersive spectroscopy (EDS) elemental mappings were collected by using a JEM-2100F STEM/EDS microscope. Nitrogen isothermal adsorption-desorption curves were measured using a Tristar II 3020 instrument at $77 \mathrm{~K}$. Raman spectra were obtained using a Renishaw INVIA micro-Raman spectroscopy system. X-ray photoelectron spectroscopy (XPS) measurements were obtained using a VG MultiLab 2000 instrument. The thermogravimetry (TG) and differential scanning calorimetry (DSC) analyses were conducted on a NETZSCH-STA449c/3/G thermoanalyzer under an air atmosphere from 30 to $600^{\circ} \mathrm{C}$ with a heating rate of $10^{\circ} \mathrm{C} \min ^{-1}$.

\section{Electrochemical measurement}

The working electrodes were prepared by mixing the assynthesized active materials, acetylene black and carboxymethyl cellulose (CMC) with a weight ratio of 7:2:1. The uniformly mixed slurry was applied to a $\mathrm{Cu}$ (for LIBs) or $\mathrm{Al}$ foil (for SIBs) and dried in a vacuum oven at $70^{\circ} \mathrm{C}$ for $6 \mathrm{~h}$. The mass loading of the active material was about $1 \mathrm{mg} \mathrm{cm}^{-2}$. The CR2016 coin cells were assembled in a glove box filled with pure argon $\left(\mathrm{H}_{2} \mathrm{O}<0.1 \mathrm{ppm}, \mathrm{O}_{2}<\right.$ 
$0.1 \mathrm{ppm}$ ). For LIBs, the lithium foils were utilized as an anode, the electrolyte consisted of $1 \mathrm{~mol} \mathrm{~L}^{-1} \mathrm{LiPF}_{6}$ dissolved in ethylene carbonate (EC)/dimethyl carbonate (DMC) with a volume ratio of 1:1, and a polypropylene film (Celgard-2300) was used as the separator. For SIBs, the sodium foils were utilized as an anode, the electrolyte consisted of $1 \mathrm{~mol} \mathrm{~L}^{-1} \mathrm{NaClO}_{4}$ dissolved in EC/DMC with a volume ratio of $1: 1$, and glass fiber membrane (GF/D What-man) was used as the separator. Galvanostatic charge/discharge cycling behavior was investigated by using a LAND CT2001A battery test system. Cyclic voltammetry (CV) and electrochemical impedance spectroscopy (EIS) plots were tested by using a VMP3 multichannel electrochemical workstation (Bio-Logic France).

\section{RESULTS AND DISCUSSION}

The XRD patterns of the precursor (FVO-NWs) and the sample after selective dissolution treatment $(\mathrm{FeOOH}-$ HNTs) are shown in Fig. S1a. All the peaks of precursor can be indexed to $\mathrm{FeVO}_{4} \cdot 1 \cdot 1 \mathrm{H}_{2} \mathrm{O}[5,19]$, while no diffraction peak was detected in the pattern of $\mathrm{FeOOH}$ HNTs after selective dissolution treatment, indicating the amorphous nature. For the XRD patterns of FVO-NWsG (Fig. S2a) and FeOOH-HNTs-G, the similar results are obtained. Raman spectrum was utilized to further determine the phase of FeOOH-HNTs (Fig. S1b). The bands located at 215 and $275 \mathrm{~cm}^{-1}$ are assigned to $\mathrm{FeOOH}$ $[20,21]$. Besides, the D and $G$ bands are detected in the Raman spectrum of FeOOH-HNTs-G, which implies the existence of graphene [6,22]. Meanwhile, thermoanalysis tests were also used to identify the component of samples after dissolution treatment (Fig. S3a). The exothermal peak at about $258^{\circ} \mathrm{C}$ is detected in the DSC curve of FeOOH-HNTs, accompanying with a mass loss of about $10.3 \%$ in the TG curve. This mass loss is close to the theoretical one for the transformation from $\mathrm{FeOOH}$ to $\mathrm{Fe}_{2} \mathrm{O}_{3}(10.1 \%)$. Thus, this exothermal peak is assigned to the decomposition of $\mathrm{FeOOH}$, and the composition of $\mathrm{FeOOH}-\mathrm{HNTs}$ can be identified as FeOOH. Based on the TG analyses of FeOOH-HNTs-G (Fig. S3b), the graphene content in FeOOH-HNTs-G is about 3.4\%. The XPS was employed to investigate the valence state of $\mathrm{Fe}$ in FeOOH-HNTs and FeOOH-HNTs-G (Fig. S4a). Two peaks, located at the bonding energies of 711.4 and $725.4 \mathrm{eV}$, are assigned to $\mathrm{Fe}^{3+} 2 \mathrm{p}_{3 / 2}$ and $2 \mathrm{p}_{1 / 2}$, respectively, in well accordance with the valence state of Fe element in $\mathrm{FeOOH}[23,24]$. Based on the XPS results, the relative atomic concentrations of $\mathrm{Fe}, \mathrm{O}, \mathrm{C}$ and $\mathrm{V}$ are $15.34 \%$, $38.19 \%, 46.33 \%$ and $0.14 \%$, respectively. Moreover, the peak of $\mathrm{V} 2 \mathrm{p}$ is absent in the XPS spectrum of $\mathrm{FeOOH}$ HNTs (Fig. S4b), demonstrating that the vanadium element has been removed completely during the dissolution treatment process or the residual vanadium element could be neglected. The above results confirm that the amorphous $\mathrm{FeOOH}$ was attained successfully after the dissolution treatment.

The FESEM image of FeOOH-HNTs (Fig. 1a) shows that the as-synthesized sample is composed of nanosheetassembled hierarchical 1D nanostructures with $100-200 \mathrm{~nm}$ in diameter. In the FESEM image of FeOOH-HNTs-G (Fig. 1b), the hierarchical 1D nanostructure covered by graphene nanosheets can be observed, revealing that the graphene has been introduced successfully. The TEM was utilized to further investigate the structure of the as-prepared samples. In the TEM image of FeOOH-HNTs (Fig. 1c), the hollow structure is obvious, and the walls of nanotubes are composed of ultra-thin nanosheets with thickness of about $2-3 \mathrm{~nm}$ (Fig. 1d). These results demonstrate that the nanosheetassembled hierarchical nanotubes were obtained. In addition, a plenty of void spaces exist between nanosheets, which could accommodate the volume change during the lithiation/delithiation process. Besides, the same hierarchical nanotube structures can also be obtained after introducing graphene (Fig. 1e). In addition, the EDS elemental mappings (Fig. 1f) reveal the uniform distribution of $\mathrm{Fe}$ and $\mathrm{O}$ elements in FeOOH-HNTs. The disorganized mapping of $\mathrm{V}$ element, indicating the vanadium content in FeOOH-HNTs is negligible, corresponding well to the EDS spectrum (Fig. S5).

The nitrogen adsorption-desorption isotherms were measured to characterize the specific surface area and porous structure of the samples (Fig. S6). The isotherms of FeOOH-HNTs are assigned to IV-type curve with $\mathrm{H} 3$ hysteresis loop, corresponding to the slit-shaped pore resulting from the assembling of plate-like subunits. This result is in well accordance with its nanosheet-assembled hierarchical NT structure revealed by SEM and TEM images. The Brunauer-Emmerr-Teller (BET) specific surface area of FeOOH-HNTs is $319.1 \mathrm{~m}^{2} \mathrm{~g}^{-1}$, much higher than that of the FVO-NWs precursor $\left(23.7 \mathrm{~m}^{2} \mathrm{~g}^{-1}\right)$. The corresponding pore size distribution plot (Fig. S6e) reveals that the sizes of pores in $\mathrm{FeOOH}-$ HNTs are mainly in $2-3$ and $10-80 \mathrm{~nm}$.

To understand the reaction mechanism and structural evolution during the dissolution treatment process, the controlled experiments with different treatment times were carried out. The precursor is composed of NWs (Fig. 2a). Moreover, with the introduction of graphene, 

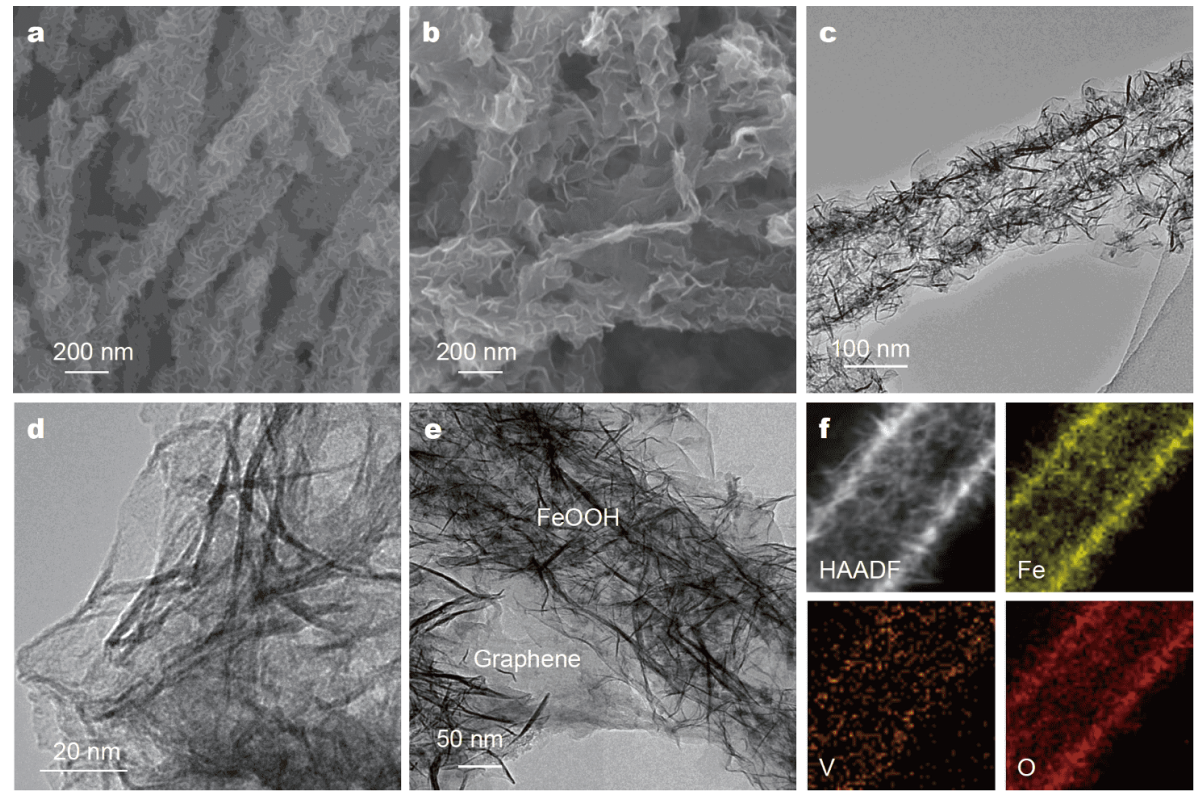

Figure 1 FESEM images of (a) FeOOH-HNTs and (b) FeOOH-HNTs-G. TEM images of (c, d) FeOOH-HNTs and (e) FeOOH-HNTs-G. (f) The high angle annular dark field (HAADF) image and the EDS elemental mappings of FeOOH-HNTs.
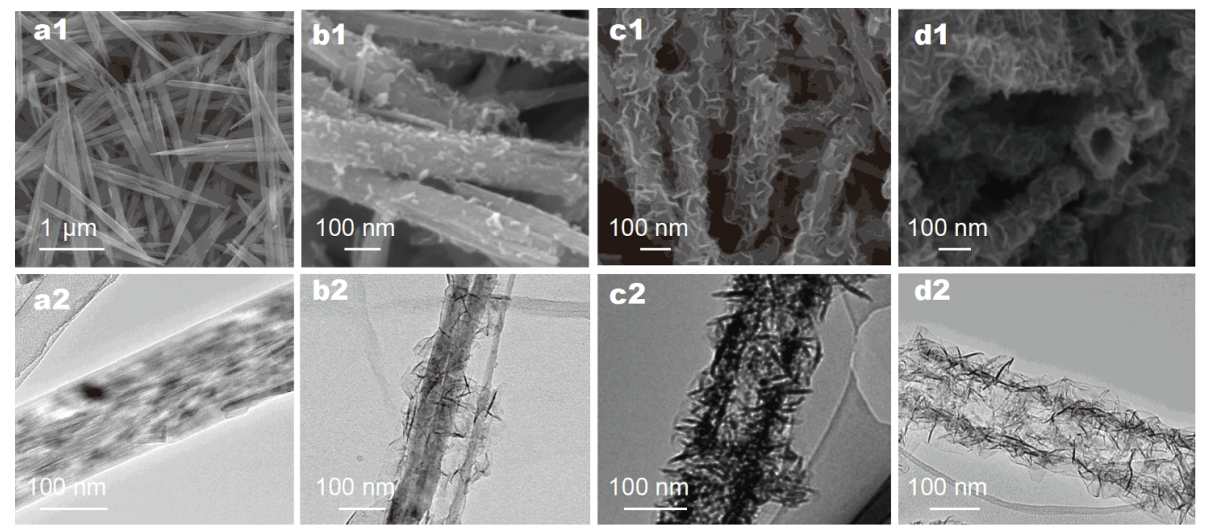

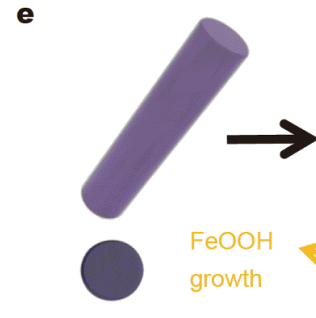

$\mathrm{FeVO}_{4} \mathrm{NWs}$

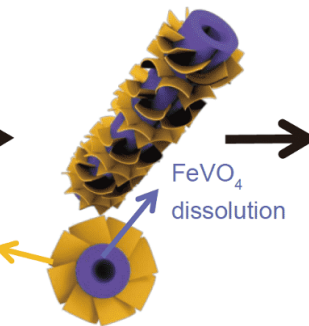

$\mathrm{FeVO}_{4} @ \mathrm{FeOOH} \mathrm{HNTS}$

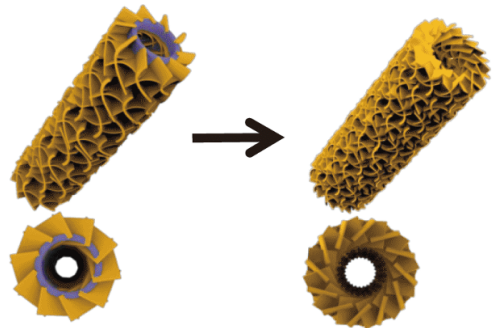

FeOOH HNTS

Figure 2 SEM and TEM images of samples after selective dissolution treatment for different times: (a) 0, (b) 20, (c) 60 and (d) 180 min. (e) Schematic illustration of structural evolution during the selective dissolution process.

the NW morphology is still maintained (Fig. S2b). At the beginning of reaction, the dissolution of NWs proceeds, accompanying with the in situ formation of nanosheets on the NW (Fig. 2b). Interestingly, the dissolution of
NWs begins from their ends (Fig. S7), which may be attributed to that the high-energy facets usually expose in the end of NWs. In addition, the EDS elemental mappings of the sample after selective dissolution treatment 
for $20 \mathrm{~min}$ (Fig. S8) display the uniform distribution of $\mathrm{Fe}, \mathrm{V}, \mathrm{O}$ elements in the NW, while only Fe and $\mathrm{O}$ elements exist in the nanosheet. These results reveal that the NWs are $\mathrm{FeVO}_{4}$ while the in situ re-formed nanosheets are $\mathrm{FeOOH}$. The nanosheets tend to grow on the NWs because the heterogeneous nucleation is usually easier than homogeneous nucleation [25]. After further dissolution treatment, the hollow structure is obtained, and the nanosheets cover the NTs (Fig. 2c). Finally, the nanosheets assembled hierarchical NTs are obtained after dissolution treatment for $180 \mathrm{~min}$ (Fig. 2d). The concentration of $\mathrm{NaOH}$ solution is an important factor for the synthesis. When etched by $\mathrm{NaOH}$ solution with lower concentration $\left(0.02 \mathrm{~mol} \mathrm{~L}^{-1}\right)$, the as-synthesized sample displays similar morphology with the precursor (Fig. S9a). While using $\mathrm{NaOH}$ solution with higher concentration $\left(0.5 \mathrm{~mol} \mathrm{~L}^{-1}\right)$, the morphology of product (Fig. S9b) is similar with that of the FeOOH-HNTs. The XRD patterns of samples after selective dissolution treatment for different times demonstrate the transition from crystalline $\mathrm{FeVO}_{4}$ to amorphous phase (Fig. S10). Besides, different from the well-ordered spots in the SAED pattern of precursor, the SAED pattern of FeOOHHNTs displays amorphous characteristic (Fig. S11). Meanwhile, the color of sample changed during the transformation (Fig. S12). The illustration for structure evolution of NWs to hierarchical NTs is shown in Fig. 2e. The transformation from FVO-NWs to FeOOH-HNTs is composed of two processes, the dissolution of $\mathrm{FeVO}_{4}$ $\mathrm{NWs}$ and the in situ growth of $\mathrm{FeOOH}$ nanosheets on NWs, and the corresponding reactions are described in Equations (1) and (2), respectively.

(Dissolution) $\mathrm{FeVO}_{4}(\mathrm{~s}) \rightarrow \mathrm{VO}_{4}{ }^{3-}+\mathrm{Fe}^{3+}$,

(Precipitation) $\mathrm{Fe}^{3+}+3 \mathrm{OH}^{-} \rightarrow \mathrm{FeOOH}(\mathrm{s})+\mathrm{H}_{2} \mathrm{O}$,

(Total) $\mathrm{FeVO}_{4}(\mathrm{~s})+3 \mathrm{OH}^{-} \rightarrow \mathrm{VO}_{4}{ }^{3-}+\mathrm{FeOOH}(\mathrm{s})+\mathrm{H}_{2} \mathrm{O}$. (3)

The equilibrium constant $(K)$ of reaction in Equation (2) is about $10^{44}$, indicating that it is a complete reaction [26]. Moreover, the proceeding of this reaction reduces the concentration of $\mathrm{Fe}^{3+}$ in solution, which will promote the dissolution of $\mathrm{FeVO}_{4}$ (Equation (1)). The total reaction is described in Equation (3), which can be considered as a selective dissolution-regrowth process.

According to the selective dissolution-regrowth mechanism, the selective dissolution strategy can also be used to fabricate other alkali-resisting metal oxides/oxyhydroxides with 1D hierarchical nanostructures from suitable bimetallic oxide NWs. To confirm the feasibility, we chose some easily available bimetallic oxide NWs as precursors to fabricate metal oxide hierarchical NWs. Firstly, the copper vanadate NWs were prepared by a simple template-free hydrothermal method (Fig. S13a). After selective dissolution treatment, the NW-assembled copper oxide NWs were obtained (Fig. 3a, b). In addition, metal molybdate NWs can also be used as precursor to fabricate metal oxide hierarchical NWs via the selective dissolution strategy due to that molybdate ion is easily soluble in the basic solution. For example, hierarchical $\mathrm{Co}_{3} \mathrm{O}_{4}$ and $\mathrm{Mn}_{3} \mathrm{O}_{4}$ NWs (Fig. 3c-f) were obtained from cobalt molybdate and manganese molybdate NWs (Fig. S13b, c), respectively. Notably, the as-obtained various hierarchical metal oxide NWs are composed of different subunits, which may result from the different crystal growth characteristics of products in $\mathrm{NaOH}$ solution. The EDS spectrum of the as-prepared manganese oxide hierarchical NWs (Fig. S14) shows that the residual Mo element can be neglected, indicating the selective dissolution of Mo. The above results demonstrate the universality of the selective dissolution-regrowth strategy. According to the reaction mechanism, the applicable condition of the selective dissolution-regrowth mechanism is that the selected precursors can be dissolved in the alkaline solution and contains at least one metal element
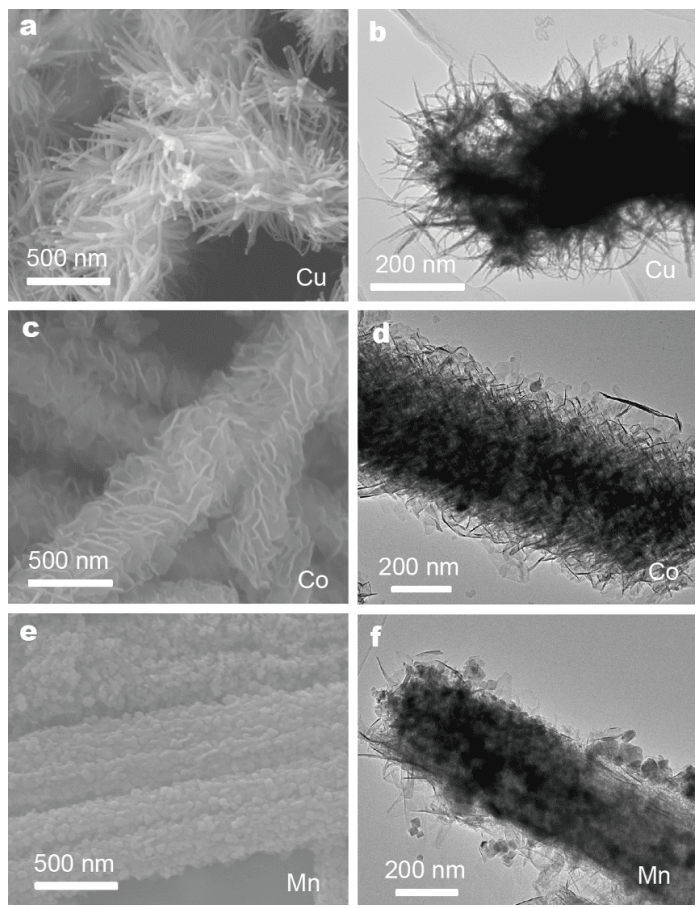

Figure 3 Other metal oxides/oxyhydroxides with 1D hierarchical nanostructures prepared by using the selective dissolution strategy. (a) FESEM and (b) TEM images of copper oxide hierarchical NWs obtained from copper vanadate NWs. (c) FESEM and (d) TEM images of cobalt oxide hierarchical NWs obtained from cobalt molybdate NWs. (e) FESEM and (f) TEM images of manganese oxide hierarchical NWs obtained from manganese molybdate NWs. 
whose oxide/oxyhydroxide can be regrown under the etching condition. In addition, the morphology of the product is dependent on the morphology of precursor, the etching condition and the properties of regrown metal oxide/oxyhydroxide.

Besides, the as-prepared Fe-based samples were evaluated as LIB anode materials. In the CV curves of FeOOH-HNTs-G (Fig. 4a), the reduction peaks at 1.93, 1.38 and $1.23 \mathrm{~V}\left(v s . \mathrm{Li}^{+} / \mathrm{Li}\right)$ in the first cathodic scan are assigned to the multi-step intercalation reaction of lithium-ion into $\mathrm{FeOOH}$, and the peak at $0.72 \mathrm{~V}$ is ascribed to the conversion reaction from $\mathrm{Li}_{x} \mathrm{FeOOH}$ to metallic Fe and lithium oxide/hydroxide and the formation of solid electrolyte interphase (SEI) films [23,27]. For the subsequent anodic scan, the shoulder peak at $1.15 \mathrm{~V}$ may be assigned to the deformation of SEI films, and the obvious peak at $1.51 \mathrm{~V}$ is associated with the deconversion reaction [23]. Besides, the shoulder peak at $2.05 \mathrm{~V}$ is attributed to the deintercalation reaction of $\mathrm{Li}_{x} \mathrm{FeOOH}[23,27]$. In the subsequent cycles, the reduction/oxidation peaks at $1.34 / 1.85$ and $0.74 / 1.53 \mathrm{~V}$ are assigned to the intercalation/deintercalation and conversion/deconversion reactions, respectively. In addition, the $\mathrm{CV}$ curves of $\mathrm{FeOOH}$ HNTs display similar shape (Fig. S15a).

Furthermore, the galvanostatic charge/discharge tests were carried out to verify the superiority of $\mathrm{FeOOH}$ HNTs-G in lithium storage. At $200 \mathrm{~mA} \mathrm{~g}^{-1}$, the FeOOH-
HNTs-G displays a high initial discharge capacity of $1485 \mathrm{~mA} \mathrm{~h} \mathrm{~g}^{-1}$, which retains at $1176 \mathrm{~mA} \mathrm{~h} \mathrm{~g}^{-1}$ after 50 cycles (Fig. $4 \mathrm{~b}$ ). This cycling performance is much better than those of both FeOOH-HNTs and FVO-NWs (Fig. S15b). The charge/discharge curves of $\mathrm{FeOOH}-$ HNTs-G (Fig. 4c) display multiple plateaus and correspond well with the CV curves. Besides, the rate performance tests for the as-synthesized samples were also performed (Fig. 4d). Even at the high current density of $2000 \mathrm{~mA} \mathrm{~g}^{-1}$, the FeOOH-HNTs-G still delivers a high capacity of $\sim 650 \mathrm{~mA} \mathrm{~h} \mathrm{~g}^{-1}$, much higher than that of FeOOH-HNTs $\left(\sim 165 \mathrm{~mA} \mathrm{~h} \mathrm{~g}^{-1}\right)$, indicating that the decoration of graphene largely enhances the rate performance. In addition, the EIS tests were carried out to analyze the kinetics (Fig. S16) and confirm the effect of graphene on conductivity. In the Nernst plots, the diameter of semicircle at high frequency region was determined by the charge transfer resistance. Obviously, the diameter of semicircle in the Nernst plots of FeOOHHNTs-G is lower than that of FeOOH-HNTs, indicating the lower charge transfer resistance for FeOOH-HNTs-G, attributed to the excellent electronic conductivity of graphene. In addition, after 1800 cycles at $1000 \mathrm{~mA} \mathrm{~g}^{-1}$ (Fig. 4e), the capacity of FeOOH-HNTs-G still remains at $463 \mathrm{~mA} \mathrm{~h} \mathrm{~g}^{-1}$ with the columbic efficiency close to $100 \%$. This cycling stability is better than most reported FeOOH-based anodes for LIBs (Table S1) [23,24,27-32].
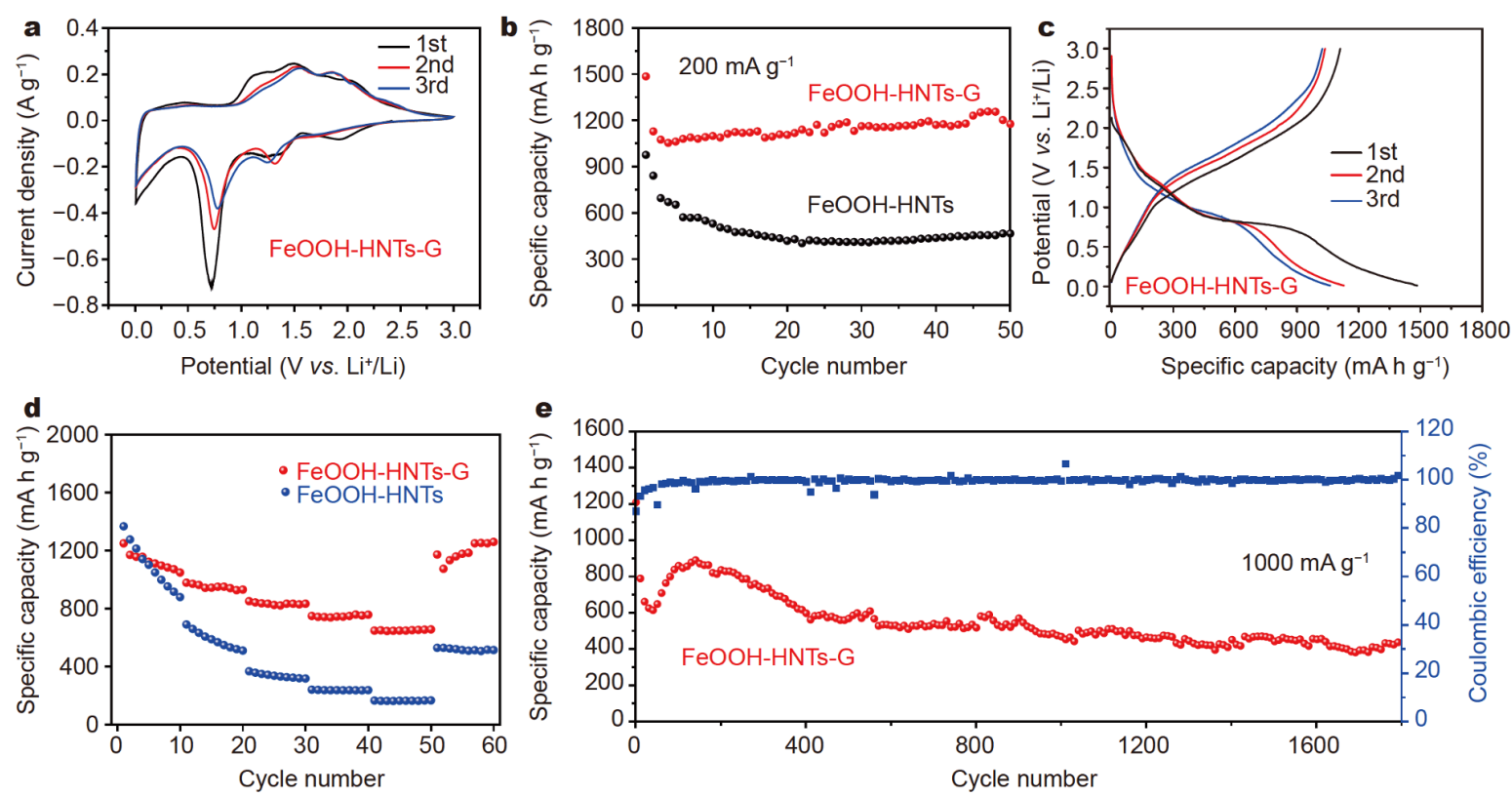

Figure 4 (a) The CVs of FeOOH-HNTs-G at scan rate of $0.1 \mathrm{mV} \mathrm{s}^{-1}$. (b) The cycling performance of FeOOH-HNTs and FeOOH-HNTs-G at $200 \mathrm{~mA} \mathrm{~g}^{-1}$. (c) The charge/discharge curves of FeOOH-HNTs-G at $200 \mathrm{~mA} \mathrm{~g}^{-1}$. (d) The rate performance of FeOOH-HNTs and FeOOH-HNTs-G. (e) The long-term cycling performance of FeOOH-HNTs-G at $1000 \mathrm{~mA} \mathrm{~g}^{-1}$. 
To the best of our knowledge, only one literature reported the longer cycling life of $\mathrm{FeOOH}$-based material, however, which was realized by adding a large content of graphite (30\%) in the electrode and the $\mathrm{FeOOH}$ content was only $50 \%$ [27]. The considerable capacity, high rate capability and cycling stability demonstrate that the assynthesized FeOOH-HNTs-G is a promising LIB anode material.

In addition, the sodium storage performance of FeOOH-HNTs-G was investigated (Fig. S17). At $100 \mathrm{~mA} \mathrm{~g}^{-1}$, a high reversible capacity of $502 \mathrm{~mA} \mathrm{~h} \mathrm{~g}^{-1}$ is obtained in the second cycle (Fig. S17a). The corresponding charge/discharge curves at $100 \mathrm{~mA} \mathrm{~g}^{-1}$ (Fig. S17b) display a sloping discharge plateau at around $1.0 \mathrm{~V}$, which matches well with the reported results $[33,34]$. The shape of charge/discharge curves of FeOOHHNTs-G as anode materials for SIBs is similar with that in LIBs, indicating the similar ion storage mechanism that high-potential intercalation and low-potential conversion reaction. However, the sodium storage capacity of FeOOH-HNTs-G is lower than its lithium storage capacity, which may be attributed to the slower kinetics of sodium ion. Even at 1000 and $2000 \mathrm{~mA} \mathrm{~g}^{-1}$, the FeOOHHNTs-G still display high capacities of 247 and $207 \mathrm{~mA} \mathrm{~h} \mathrm{~g}^{-1}$, respectively. This rate performance is the best one compared with the reported $\mathrm{FeOOH}$-based anode materials for SIBs $[33,34]$. In addition, the cycling performance of FeOOH-HNTs-G as anode materials for SIBs has also been evaluated (Fig. S17c). After 100 cycles at $500 \mathrm{~mA} \mathrm{~g}^{-1}$, the FeOOH-HNTs-G exhibits a capacity of $244 \mathrm{~mA} \mathrm{~h} \mathrm{~g}^{-1}$.

The superior lithium/sodium storage performance of FeOOH-HNTs-G is attributed to the combination of nanoscale and atomic level structure. The ultra-thin nanosheets provide short ion-diffusion pathway and large electrode-electrolyte interface, and graphene facilitates the electronic conduction, which are beneficial to realizing high capacity and rate performance. In addition, the hierarchical hollow nanostructure and disordered atomic frameworks enhance the structural stability during the cycling process by providing void space to accommodate the volumetric change.

\section{CONCLUSIONS}

In summary, the selective dissolution-regrowth strategy was proposed and demonstrated as a facile method to construct 1D hierarchical metal oxides/oxyhydroxides for excellent lithium storage. The internal mechanism and structural evolution during the formation of amorphous $\mathrm{FeOOH}-\mathrm{HNTs}$ (i.e., the dissolution of FVO-NWs and the in situ regrowth of $\mathrm{FeOOH}$ nanosheets) was confirmed. And the universality of this strategy was confirmed by the syntheses of various hierarchical metal oxides (copper oxide, manganese oxide and cobalt oxide) NWs. As a representative, owing to the optimal 1D hierarchical hollow structure and inherent amorphous atomic-structure, the graphene-decorated amorphous FeOOH-HNTs exhibit outstanding Li-ion storage performance with enhanced rate capability $\left(\sim 650 \mathrm{~mA} \mathrm{~h} \mathrm{~g}^{-1}\right.$ at $\left.2000 \mathrm{~mA} \mathrm{~g}^{-1}\right)$ and cycling stability $\left(463 \mathrm{~mA} \mathrm{~h} \mathrm{~g}^{-1}\right.$ after 1800 cycles at $1000 \mathrm{~mA} \mathrm{~g}^{-1}$ ). More importantly, the presented selective dissolution-regrowth strategy here is universal and likely to synthesize other hierarchical nanostructures for various energy-related applications in the future.

\section{Received 25 February 2020; accepted 7 April 2020;}

published online 21 May 2020

1 Lee J, Kitchaev DA, Kwon DH, et al. Reversible $\mathrm{Mn}^{2+} / \mathrm{Mn}^{4+}$ double redox in lithium-excess cathode materials. Nature, 2018, 556: 185190

2 Larcher D, Tarascon JM. Towards greener and more sustainable batteries for electrical energy storage. Nat Chem, 2015, 7: 19-29

3 Kwade A, Haselrieder W, Leithoff R, et al. Current status and challenges for automotive battery production technologies. Nat Energy, 2018, 3: 290-300

4 Jiang Z, Xie H, Wang S, et al. Perovskite membranes with vertically aligned microchannels for all-solid-state lithium batteries. Adv Energy Mater, 2018, 8: 1801433

5 An $\mathrm{Q}, \mathrm{Lv} \mathrm{F}$, Liu $\mathrm{Q}$, et al. Amorphous vanadium oxide matrixes supporting hierarchical porous $\mathrm{Fe}_{3} \mathrm{O}_{4}$ /graphene nanowires as a high-rate lithium storage anode. Nano Lett, 2014, 14: 6250-6256

6 Xiong F, Cai Z, Qu L, et al. Three-dimensional crumpled reduced graphene oxide/ $\mathrm{MoS}_{2}$ nanoflowers: A stable anode for lithium-ion batteries. ACS Appl Mater Interfaces, 2015, 7: 12625-12630

7 Croguennec L, Palacin MR. Recent achievements on inorganic electrode materials for lithium-ion batteries. J Am Chem Soc, 2015, 137: $3140-3156$

8 Obrovac MN, Chevrier VL. Alloy negative electrodes for Li-ion batteries. Chem Rev, 2014, 114: 11444-11502

9 Wei Q, Xiong F, Tan S, et al. Porous one-dimensional nanomaterials: Design, fabrication and applications in electrochemical energy storage. Adv Mater, 2017, 29: 1602300

10 Mai L, Tian X, Xu X, et al. Nanowire electrodes for electrochemical energy storage devices. Chem Rev, 2014, 114: 11828-11862

11 Zhao Q, Guo Z, Wu Y, et al. Hierarchical flower-like spinel manganese-based oxide nanosheets for high-performance lithium ion battery. Sci China Mater, 2019, 62: 1385-1392

12 Zheng M, Xiao X, Li L, et al. Hierarchically nanostructured transition metal oxides for supercapacitors. Sci China Mater, 2017, 61: 185-209

13 Liu J, Zheng M, Shi X, et al. Amorphous FeOOH quantum dots assembled mesoporous film anchored on graphene nanosheets with superior electrochemical performance for supercapacitors. Adv Funct Mater, 2016, 26: 919-930

14 Li D, Zhou J, Chen X, et al. Amorphous $\mathrm{Fe}_{2} \mathrm{O}_{3} /$ graphene composite nanosheets with enhanced electrochemical performance for so- 
dium-ion battery. ACS Appl Mater Interfaces, 2016, 8: 3089930907

15 Lee NW, Jung JW, Lee JS, et al. Facile and fast Na-ion intercalation employing amorphous black $\mathrm{TiO}_{2-x} / \mathrm{C}$ composite nanofiber anodes. Electrochim Acta, 2018, 263: 417-425

16 Niu X, Zhang Y, Tan L, et al. Amorphous $\mathrm{FeVO}_{4}$ as a promising anode material for potassium-ion batteries. Energy Storage Mater, 2019, 22: 160-167

17 Jiang Y, Zhang D, Li Y, et al. Amorphous $\mathrm{Fe}_{2} \mathrm{O}_{3}$ as a high-capacity, high-rate and long-life anode material for lithium ion batteries. Nano Energy, 2014, 4: 23-30

18 Xiong F, Tao H, Yue Y. Role of amorphous phases in enhancing performances of electrode materials for alkali ion batteries. Front Mater, 2020, 6: 328

19 Kaneti YV, Zhang Z, Yue J, et al. Porous $\mathrm{FeVO}_{4}$ nanorods: Synthesis, characterization, and gas-sensing properties toward volatile organic compounds. J Nanopart Res, 2013, 15: 1948

20 Luo W, Jiang C, Li Y, et al. Highly crystallized $\alpha-\mathrm{FeOOH}$ for a stable and efficient oxygen evolution reaction. J Mater Chem A, 2017, 5: 2021-2028

21 de Faria DLA, Venâncio Silva S, de Oliveira MT. Raman microspectroscopy of some iron oxides and oxyhydroxides. J Raman Spectrosc, 1997, 28: 873-878

22 Xiong $\mathrm{F}$, Tan $\mathrm{S}$, Wei $\mathrm{Q}$, et al. Three-dimensional graphene frameworks wrapped $\mathrm{Li}_{3} \mathrm{~V}_{2}\left(\mathrm{PO}_{4}\right)_{3}$ with reversible topotactic sodiumion storage. Nano Energy, 2017, 32: 347-352

23 Qi H, Cao L, Li J, et al. High pseudocapacitance in FeOOH/rGO composites with superior performance for high rate anode in $\mathrm{Li}$ ion battery. ACS Appl Mater Interfaces, 2016, 8: 35253-35263

24 Sun Y, Hu X, Luo W, et al. Synthesis of amorphous FeOOH/ reduced graphene oxide composite by infrared irradiation and its superior lithium storage performance. ACS Appl Mater Interfaces, 2013, 5: 10145-10150

25 Sun Y. Interfaced heterogeneous nanodimers. Natl Sci Rev, 2015, 2: 329-348

26 Misawa T. The thermodynamic consideration for $\mathrm{Fe}-\mathrm{H}_{2} \mathrm{O}$ system at $25^{\circ} \mathrm{C}$. Corrosion Sci, $1973,13: 659-676$

27 Yu L, Xi S, Wei C, et al. Superior lithium storage properties of $\beta$ FeOOH. Adv Energy Mater, 2015, 5: 1401517

28 Song Y, Cao Y, Wang J, et al. Bottom-up approach design, band structure, and lithium storage properties of atomically thin $\gamma$ FeOOH nanosheets. ACS Appl Mater Interfaces, 2016, 8: 2133421342

29 Zhang C, Zhu J, Rui X, et al. Synthesis of hexagonal-symmetry airon oxyhydroxide crystals using reduced graphene oxide as a surfactant and their Li storage properties. CrystEngComm, 2012, 14: $147-153$

30 Zou M, Wen W, Li J, et al. Nano-crystalline FeOOH mixed with SWNT matrix as a superior anode material for lithium batteries. J Energy Chem, 2014, 23: 513-518

31 Peng S, Yu L, Sun M, et al. Bunched akaganeite nanorod arrays: Preparation and high-performance for flexible lithium-ion batteries. J Power Sources, 2015, 296: 237-244

32 Zhang X, Du Y. Gelatin assisted wet chemistry synthesis of high quality $\beta$-FeOOH nanorods anchored on graphene nanosheets with superior lithium-ion battery application. RSC Adv, 2016, 6: 17504-17509

33 Yu L, Wang LP, Xi S, et al. $\beta$-FeOOH: An earth-abundant highcapacity negative electrode material for sodium-ion batteries. Chem Mater, 2015, 27: 5340-5348
34 Zhang M, Han D, Lu P. PEDOT encapsulated $\beta$-FeOOH nanorods: Synthesis, characterization and application for sodium-ion batteries. Electrochim Acta, 2017, 238: 330-336

Acknowledgements This work was supported by the National Key Research and Development Program of China (2017YFE0127600, 2016YFA0202600), the Program of Introducing Talents of Discipline to Universities (B17034), the National Natural Science Foundation of China (51521001 and 51602239), the National Natural Science Fund for Distinguished Young Scholars (51425204), Hubei Provincial Natural Science Foundation (2016CFB267), and the Fundamental Research Funds for the Central Universities (WUT: 2017-YB-001).

Author contributions Mai L, Guo S, An Q, Lv F and Xiong F conceived the study. Lv F, Tang C and Xiong F carried out the experiments. Xiong F, Lv F, Tang C, Zhang P and Tan S participated in the data analysis. Xiong F and Lv F wrote the manuscript and Mai L, Guo S and An Q provided insights for the experiments and supervised the research. Tang $\mathrm{C}$, Zhang $\mathrm{P}$ and Tan $\mathrm{S}$ modified the manuscript. All authors approved the final manuscript.

Conflict of interest The authors declare no conflict of interest.

Supplementary information Supporting data are available in the online version of the paper.

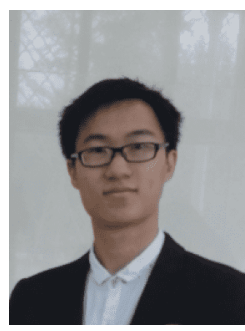

Fangyu Xiong received his BSc degree in material physics from Wuhan University of Technology (WUT) in 2016. He is currently pursuing his $\mathrm{PhD}$ degree and his current research interest focuses on the electrode materials for emerging energy storage devices.

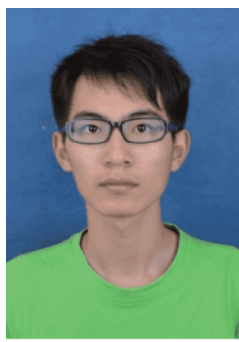

Fan Lv is currently a $\mathrm{PhD}$ student in the Department of Materials Science and Engineering, Peking University under the supervision of Prof. Shaojun Guo. His current research interests focus on the development of nanostructured advanced energy materials for electrocatalysis.

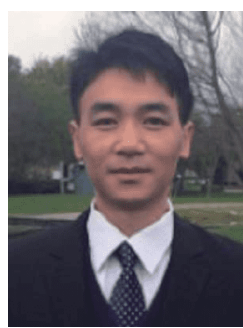

Qinyou An is Associate Professor of materials science and engineering at WUT. He received his $\mathrm{PhD}$ degree from WUT in 2014. He carried out his postdoctoral research in the Laboratory of Prof. Yan Yao at the University of Houston in 2014-2015. Currently, his research interest includes energy storage materials and devices. 


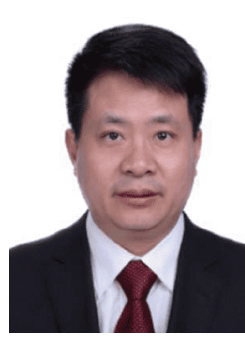

Liqiang Mai is the Chair Professor of materials science and engineering at WUT. He received his $\mathrm{PhD}$ from WUT in 2004. He carried out his postdoctoral research in the Laboratory of Prof. Zhonglin Wang at Georgia Institute of Technology in 2006-2007 and worked as an advanced research scholar in the Laboratory of Prof. Charles M. Lieber at Harvard University in 2008-2011. His current research interests focus on nanowire materials and devices for energy storage.

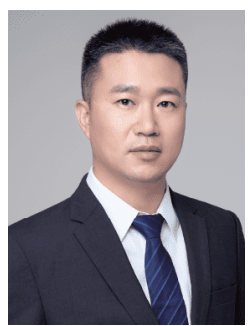

Shaojun Guo received his BSc degree from Jilin University (2005) and $\mathrm{PhD}$ degree from the Chinese Academy of Sciences (2010). He worked as a postdoctoral researcher associate at Brown University (2011-2013) and as a prestigious Oppenheimer Distinguished Fellow at Los Alamos National Laboratory (2013-2015). He joined the College of Engineering, Peking University in 2015 and is currently a Professor. His research interests focus on engineering nanocrystals and 2D materials for catalysis, renewable energy, optoelectronics and biosensors.
选择性溶解-再生长策略原位构筑非晶羟基氧化 铁分级纳米管增强储锂性能

熊方宇 ${ }^{1 \dagger}$, 吕帆 ${ }^{2 \dagger}$, 汤臣 ${ }^{1}$, 张鹏飞 ${ }^{1}$, 谭双双 ${ }^{1}$, 安琴友 ${ }^{1,3^{*}}$, 郭少军 ${ }^{2,4,5^{*}}$, 麦立强 ${ }^{1,3}$

摘要 低成本、高容量金属氧化物/氢氧化物作为具有更高能量密 度的锂离子电池的负极材料时具有显著优势. 合理调控金属氧化 物/氢氧化物的中空结构和无序的原子框架是提高其电化学性能的 有效途径. 本文提出了一种快速碱刻蚀方法, 实现了非晶 $\mathrm{FeOOH}$ 分 级纳米管的原位构筑. 得益于增强的电子/离子动力学和对循环过 程中的体积变化的有效缓冲, 石墨烯修饰的非晶 $\mathrm{FeOOH}$ 分级纳米 管展现出高倍率性能(在 $2000 \mathrm{~mA} \mathrm{~g}^{-1}$ 的电流密度下容量可达 650 $\mathrm{mA} \mathrm{h} \mathrm{g}^{-1}$ )和优异的循环稳定性(循环 1800 次后容量仍保持在 463 $\mathrm{mA} \mathrm{h} \mathrm{g}$ ), 在目前报道的 $\mathrm{FeOOH}$ 基材料中处于领先水平. 研究表 明碱刻蚀过程中的选择性溶解-再生长机制, 即 $\mathrm{FeVO}_{4}$ 的溶解和 $\mathrm{FeOOH}$ 的原位成核再生长在非晶 $\mathrm{FeOOH}$ 分级纳米管的合成过程 中具有重要作用. 此外, 这种选择性溶解-再生长机制是一种合成具 有一维分级纳米结构的金属(例如 $\mathrm{Fe}, \mathrm{Mn}, \mathrm{Co}$ 和 $\mathrm{Cu}$ )氧化物/差基氧 化物的普适方法. 